\title{
Method for Tealeaves Quality Estimation Through Measurements of Degree of Polarization, Leaf Area Index, Photosynthesis Available Radiance and Normalized Difference Vegetation Index for Characterization of Tealeaves
}

\author{
Kohei Arai ${ }^{1}$ \\ ${ }^{1}$ Graduate School of Science and Engineering \\ Saga University \\ Saga City, Japan
}

\begin{abstract}
Method for tealeaves quality estimation through measurements of Degree of Polarization: DP, Leaf Area Index: LAI, Photosynthesis Available Radiance: PAR and Normalized Difference Vegetation Index: NDVI for characterization of tealeaves is proposed. The method allows estimations of PAR, NDVI, Grow Index: GI by using measured Degree of Polarization: DP of tealeaves. Through experiments at the tea farm areas, it is found that the proposed method is validated. Also, the method is validated through Monte Carlo Ray Tracing: MCRT simulations for discrimination between prolate and oblate shapes of tealeaves. In accordance with growing tealeaves, prolate shape of tealeaves changes their shape to oblate shape. Therefore, growing stage can be estimated with DP measurements.
\end{abstract}

Keywords-adjucency effect; nonlinear mixed pixel model; Monte Carlo method; Ray tracing method

\section{INTRODUCTION}

It is highly desired to monitor vitality of crops in agricultural areas automatically with appropriate measuring instruments in order to manage agricultural area in an efficient manner. It is also required to monitor not only quality but also quantity of vegetations in the farmlands. Vegetation monitoring is attempted with red and photographic cameras [1]. Grow rate monitoring is also attempted with spectral observation [2].

This paper deals with automatic monitoring of tealeaves quality with polarization films attached visible and near infrared cameras. Also, this paper proposes a method that allows estimation of total nitrogen and fiber contents in tealeaves as an example. Furthermore, this paper describes a method and system for estimation of quantity of crop products by using not only Vegetation Cover: VC and Normalized Difference Vegetation Index: NDVI but also Bi-directional Reflectance Distribution Function: BRDF because the VC and NDVI represent vegetated area while BRDF represents vegetation mass, or layered leaves.
Total nitrogen content corresponds to amid acid which is highly correlated to Theanine: 2-Amino-4-(ethylcarbamoyl) butyric acid for tealeaves so that total nitrogen is highly correlated to tea taste. Meanwhile fiber content in tealeaves has a negative correlation to tea taste. Near Infrared: NIR camera data shows a good correlation to total nitrogen and fiber contents in tealeaves so that tealeaves quality can be monitored with network NIR cameras. It is also possible to estimate total nitrogen and fiber contents in leaves with the acquired camera data. Moreover, VC, NDVI, BRDF of tealeaves has a good correlation to grow index of tealeaves so that it is possible to monitor expected harvest amount and quality of tealeaves with network camera data. BRDF monitoring is well known as a method for vegetation growth [3],[4]. On the other hand, degree of polarization of vegetation is attempted to use for vegetation monitoring [5], in particular, Leaf Area Index: LAI together with new tealeaves growth monitoring with BRDF measurements [6].

Other index for representation of tealeaves quality is Photosynthesis Available Radiance: PAR. There is relation among indexes. The proposed method and system is to monitor tealeaves quality with polarization films covered visible and near infrared cameras. Relation between Degree of Polarization: DP and the other indexes, NDVI, LAI, PAR is clarified in this paper.

In particular, method for estimation of Grow Index: GI derived from DP is validated through Monte Carlo Ray Tracing: MCRT [7]-[16] simulations.

Tea estate monitoring system with network cameras, meteorological robots and the aforementioned cameras is proposed in the following section followed by proposed estimation methods for total nitrogen and fiber contents with network camera data. The proposed method is validated with some experimental results conducted at tea farm areas which are situated in Saga prefecture, Kyushu Japan. Finally, concluding remarks is followed with some discussions. 


\section{PROPOSED METHOD AND SYSTEM}

\section{A. Proposed System}

Figure 1 shows the proposed system for monitoring of tealeaves quality with polarization films attached visible and Near Infrared: NIR cameras. The cameras are situated at 5-6 m above the ground surface. Visible and NIR network cameras are equipped on the pole in order to look down with 10-80 degrees of incident angle (these angles allow BRDF measurements). The pole is used for avoid frosty damage to the tealeaves using fan mounted on the pole (for convection of boundary layer air). With these network cameras, reflectance in the wavelength region of $550 \mathrm{~nm}$ (red color) and $870 \mathrm{~nm}$ (NIR) are measured together with BRDF assuming that vegetated areas are homogeneous and flat. BRDF is used for estimation of Grow Index (GI) and BRDF correction from the measured reflectance of the tealeaves.

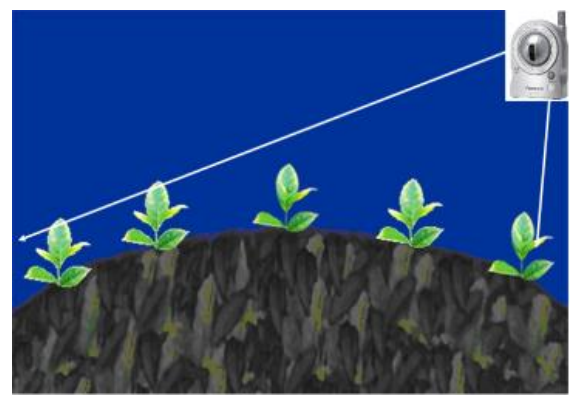

Fig. 1. Proposed system for monitoring of tealeaves quality with polarization films attached visible and Near Infrared: NIR cameras.

Figure 2 shows an example of acquired visible camera images of tea farm area which is situated in Ureshino city, Saga Prefecture, Kyushu, Japan. With these cameras, $p$ and $s$ polarized imagery data can be acquired. Using these polarized imagery data ( $\mathrm{p}$ and $\mathrm{s}$ components of data, $\mathrm{p}$ and $\mathrm{s}$ ), Degree of Polarization: DP can be estimated with Equation (1).

$\mathrm{DP}=(\mathrm{p}-\mathrm{s}) /(\mathrm{p}+\mathrm{s})$

\section{B. Crop Quality (Nitrogen Contents)Mmonitoring from Space}

Nitrogen content is one of representatives of crop quality. Nitrogen content is proportional to Theanine: 2-Amino-4(ethylcarbamoyl) butyric acid. Because Theanine rich tealeaves taste good, nitrogen content in tealeaves is representative of tealeaves quality. Theanine: 2-Amino-4(ethylcarbamoyl) butyric acid that is highly correlated to nitrogen contents in new tealeaves are changed to catechin [17],[18],[19] due to sun light. In accordance with sunlight, new tealeaves grow up so that there is a most appropriate time for harvest in order to maximize amount and taste of new tealeaves simultaneously.

Grow Index: GI is other representative for tealeaves growing. It can be measured with Green Meter: GM values of tealeaves. Leaf Area Index: LAI of tealeaves and Photosynthesis Available Radiance: PAR is another representative of harvesting amount and tealeaves quality. Through monitoring these GI, LAI, it is possible to find growing status while tealeaves quality can be found through GM and PAR monitoring.

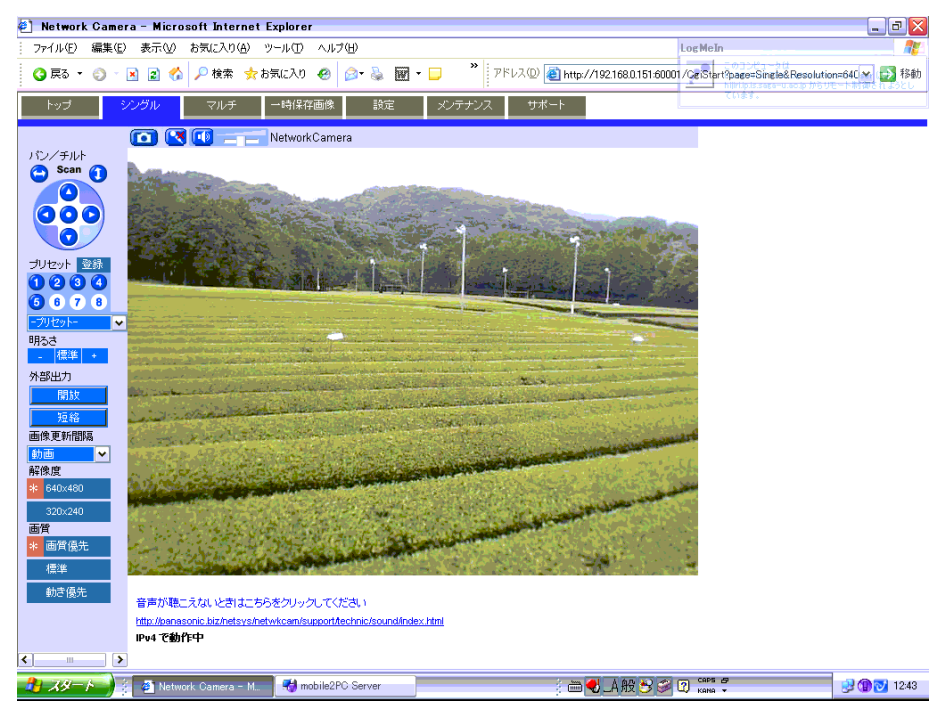

Fig. 2. Example of farmland monitored visible camera image.

\section{Grow Stage Monitoring}

Grow stage can be monitored by measuring shape of tealeaves. New tealeaves are borne from the matured tealeaves which are situated in Japan in the late of March or the begging of April. Tips of the new borne tealeaves are directed to the sky. Then tips of the tealeaves are directed to horizon in accordance with growing stage. Directions of tealeaves can be discriminated through DP measurements. Therefore, grow stage monitoring can be done with DP measurements.

\section{SimUlations}

\section{A. Monte Carlo Ray Tracing: MCRT Simulation Method}

In order to validate the proposed method, MCRT simulation study and field experimental study is conducted. MCRT allows simulation of polarization characteristics of sea surface with designated parameters of the atmospheric conditions and sea surface and sea water conditions. Illustrative view of MCRT is shown in Figure 3.

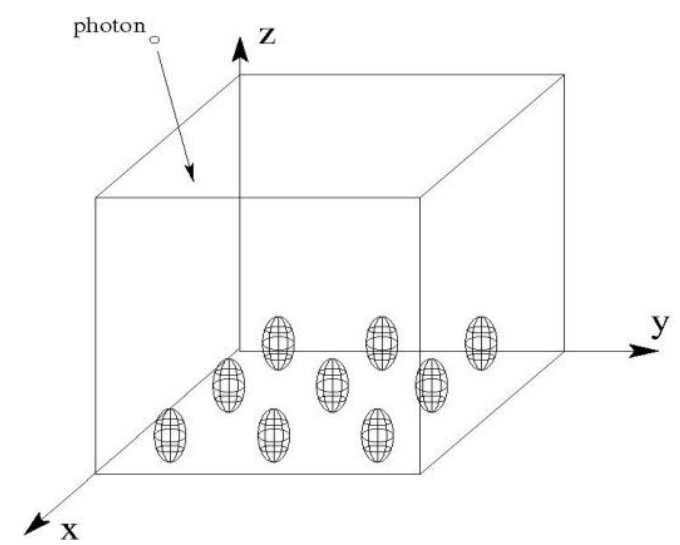

Fig. 3. Monte Carlo Ray Tracing: MCRT Simulation Cell

Photon from the sun is input from the top of the atmosphere (the top of the simulation cell). Travel length of the photon is calculated with optical depth of the atmospheric molecule and that of aerosol. There are two components in the 
atmosphere; molecule and aerosol particles while three are also two components, water and particles; suspended solid and phytoplankton in the ocean. When the photon meets molecule or aerosol (the meeting probability with molecule and aerosol depends on their optical depth), then the photon scattered in accordance with scattering properties of molecule and aerosol.

The scattering property is characterized with phase function ${ }^{1}$. In the visible to near infrared wavelength region, the scattering by molecule is followed by Rayleigh scattering law [20] while that by aerosol is followed by Mie scattering law [20].

On the ground surface of MCRT model, there are 2D aligned tealeaves. The shape of these tealeaves is prolate or oblate shapes which are shown in Figure 4.

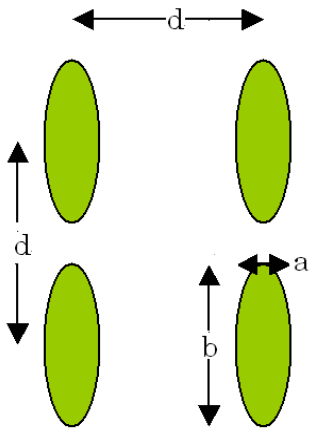

(a) Prolate shape of spheroid model of corn type of crops

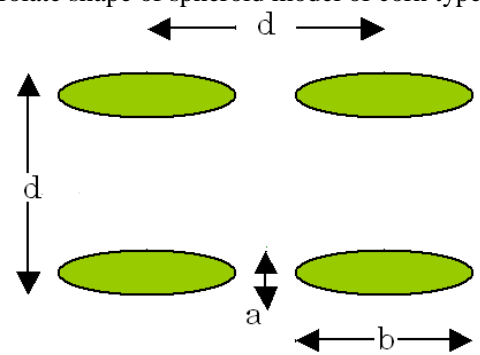

(b) Oblate shape of spheroid model of pea type of crops

Fig. 4. Illustrative view of computer simulation cell that consists of $50 \mathrm{~km}$ by $50 \mathrm{~km}$ by $50 \mathrm{~km}$.

Oblate and prolate spheroid shapes of leaves are two dimensionally aligned on ground surface. Horizontal and vertical length of leaves is "a" and "b" while distance between leaves is " $\mathrm{d}$ ". The shape of new borne tealeaves from elderly tealeaves is prolate while that of grown-up tealeaves is oblate. Therefore, it is capable to discriminate between new and old tealeaves by using shape factor between prolate and oblate shapes of tealeaves of polarization characteristics. As shown in Figure 5, the shape of tealeaves is changed from prolate to oblate in accordance with their age.

Figure 6 shows DP of the surface consists of prolate and oblate shape of leaves for the solar zenith angle of 60 degree. Figure 6(a) shows DP for the leaves with the different reflectance $(0.215$ for $\mathrm{p}$ and 0.46 for $\mathrm{s}$ polarizations for prolate and 0.22 for $\mathrm{p}$ and 0.21 for $\mathrm{s}$ polarizations for oblate) from the surface, at wavelength of $730 \mathrm{~nm}$ while Figure 6(b) shows DP for the same leaf reflectance of 0.22 for $p$ and 0.21 for $s$ polarizations for both. Prefatory note denotes long and short radius and ( $\mathrm{p}$ ) and ( $\mathrm{s}$ ) indicates $\mathrm{p}$ and s polarized radiance.

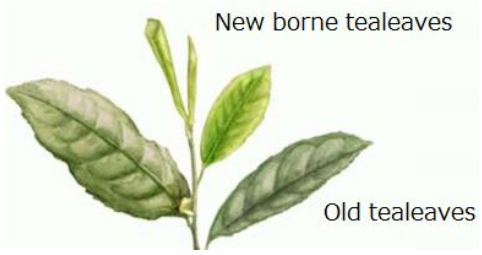

Fig. 5. Shapes of new borne tealeaves and old tealeaves

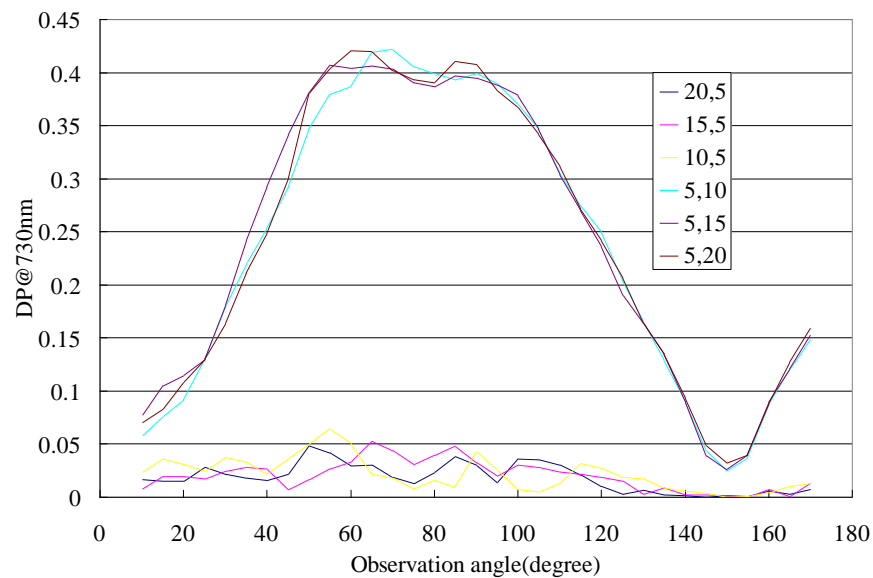

(a) DP for the different shape of spheroid with the different reflectance ( 0.215 for $\mathrm{p}$ and 0.46 for $\mathrm{s}$ polarizations for prolate and 0.22 for $\mathrm{p}$ and 0.21 for s polarization for oblate)

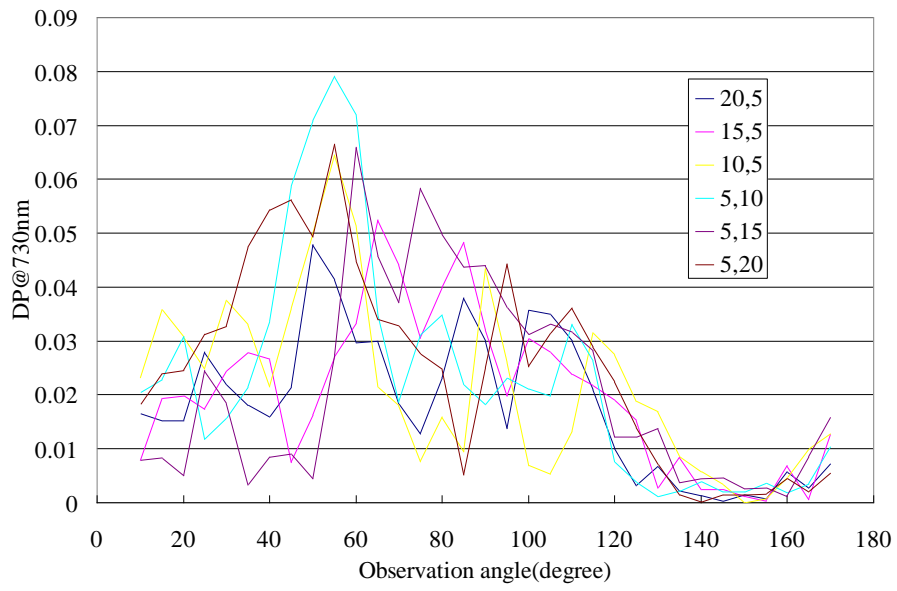

(b) DP for the different shape of spheroid with the same reflectance $(0.22$ for $\mathrm{p}$ and 0.21 for s polarizations for both)

Fig. 6. Degree of Polarization (DP) and the number of photons which correspond to $\mathrm{p}$ and $\mathrm{s}$ polarized radiance from the surface consists of prolate and oblate shape of leaves for the solar zenith angle of 60 degree. (a) and (b) shows the number of photons and DP for the leaves with the different reflectance $(0.215$ for $\mathrm{p}$ and 0.46 for s polarizations for prolate and 0.22 for $\mathrm{p}$ and 0.21 for s polarizations for oblate) from the surface, at wavelength of $730 \mathrm{~nm}$ while (c) and (d) those for the same leaf reflectance of 0.22 for $\mathrm{p}$ and 0.21 for s polarizations for both. Prefatory note denotes long and short radius and $(\mathrm{p})$ and ( $\mathrm{s}$ ) indicates $\mathrm{p}$ and $\mathrm{s}$ polarized radiance.

\footnotetext{
${ }^{1}$ http://ejje.weblio.jp/content/phase+function
} 
Meanwhile, Figure 7 shows DP of the surface consists of prolate and oblate shape of leaves for the solar zenith angle of 60 degree. Figure 7(a) shows DP for the leaves with the different reflectance $(0.1$ for $\mathrm{p}$ and 0.5 for $\mathrm{s}$ polarizations for prolate and 0.08 for $\mathrm{p}$ and 0.21 for $\mathrm{s}$ polarizations for oblate) from the surface, at wavelength of $550 \mathrm{~nm}$ while Figure 7(b) shows DP of the same leaf reflectance of 0.1 for $p$ and 0.5 for $\mathrm{s}$ polarizations for both.

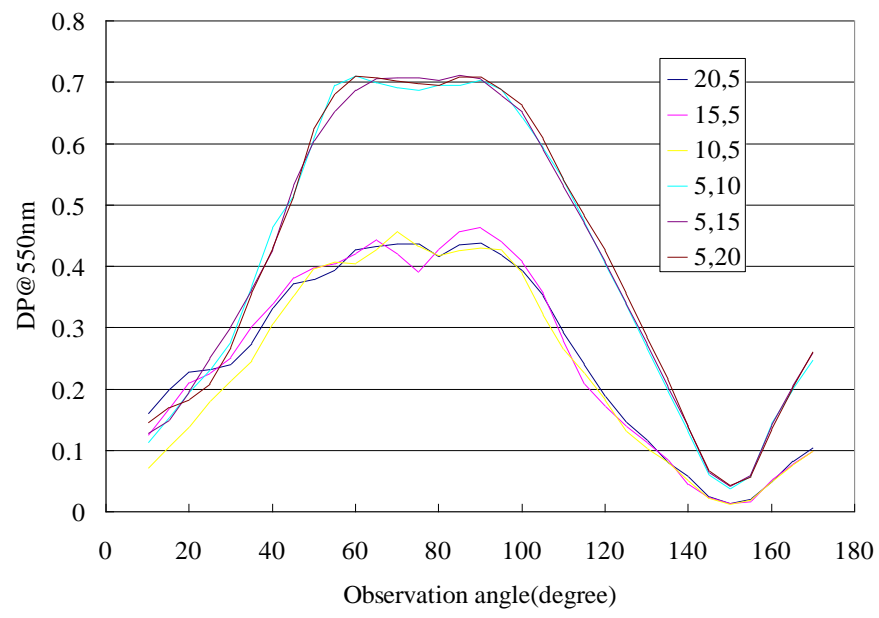

(a) DP for the different shape of spheroid with the different reflectance $(0.1$ for $\mathrm{p}$ and 0.5 for $\mathrm{s}$ polarizations for prolate and 0.08 for $\mathrm{p}$ and 0.21 for $\mathrm{s}$ polarization for oblate)

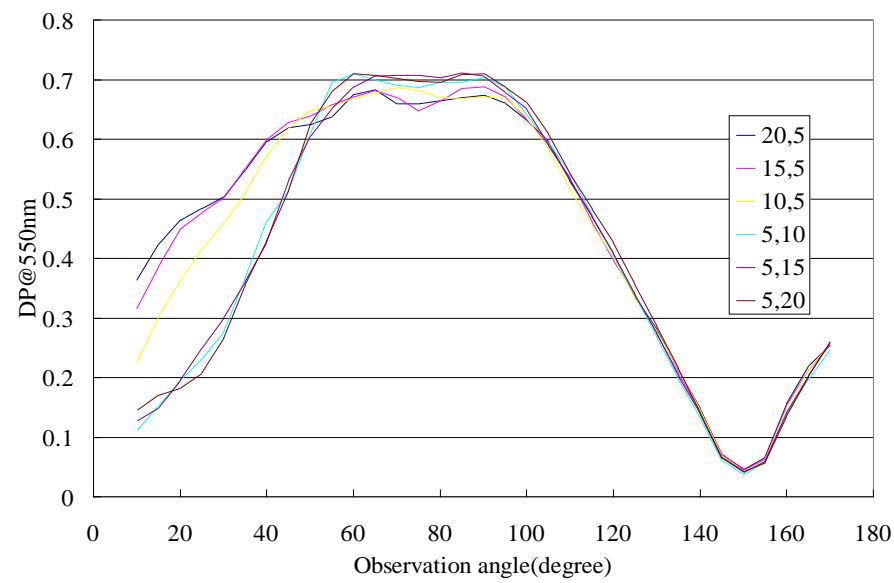

(b)DP for the different shape of spheroid with the same reflectance $(0.1$ for $\mathrm{p}$ and 0.5 for s polarizations for both)

Fig. 7. Degree of Polarization (DP) and the number of photons which correspond to $\mathrm{p}$ and $\mathrm{s}$ polarized radiance from the surface consists of prolate and oblate shape of leaves for the solar zenith angle of 60 degree. (a) and (b) shows the number of photons and DP for the leaves with the different reflectance ( 0.1 for $\mathrm{p}$ and 0.5 for $\mathrm{s}$ polarizations for prolate and 0.08 for $\mathrm{p}$ and 0.21 for s polarizations for oblate) from the surface, at wavelength of $550 \mathrm{~nm}$ while (c) and (d) those for the same leaf reflectance of 0.1 for $\mathrm{p}$ and 0.5 for $\mathrm{s}$ polarizations for both. Prefatory note denotes long and short radius and (p) and (s) indicates $\mathrm{p}$ and s polarized radiance.

It is found that the difference between prolate and oblate shapes of tealeaves at $550 \mathrm{~nm}$ (green band) is much clear than that of $730 \mathrm{~nm}$ (near infrared band) through comparison between Figure 6 and 7. It is also found that the difference of $\mathrm{DP}$ for different reflectance for $\mathrm{p}$ and s polarized reflectance is much greater than that for same reflectance. DP difference between prolate and oblate shapes of tealeaves for both same and different reflectance at $\mathrm{p}$ and $\mathrm{s}$ polarization at around 30 degree of observation angle shows relatively clear than that for the other observation angle. Therefore, 30 degree of observation angle would be the best for DP observations.

\section{EXPERIMENTS}

\section{A. Measuremeng Instruments}

Tracing Radiation and Canopy Architecture: TRAC of Leaf Area Index Measuring Instrument manufactured by The Third Wave Engineering, Canada is used for the experiment. Wavelength coverage ranges from 400 to $700 \mathrm{~nm}$. Outlook of the TRAC is shown in Figure 8.
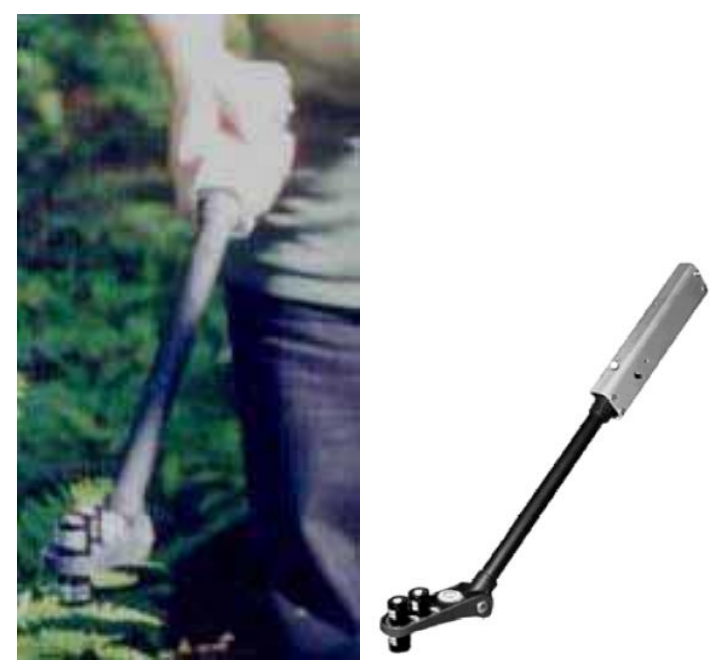

Fig. 8. Outlook of the TRAC for measurement of LAI

Meanwhile the outlook of the polarization film attached camera with fish eye lens is shown in Figure 9.

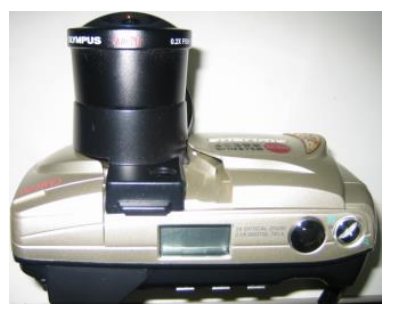

(a) Digital camera with fish eye lens

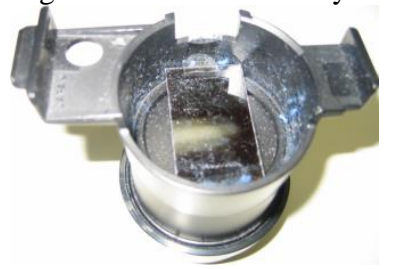

(b) Polarization film attached fish eye lens

Fig. 9. Camera for polarization measurements

Meanwhile, outlook of the measurement instrument for surface reflectance, PAR, NDVI is shown in Figure 10 while major specification of the measuring instrument is shown in Table 1. 


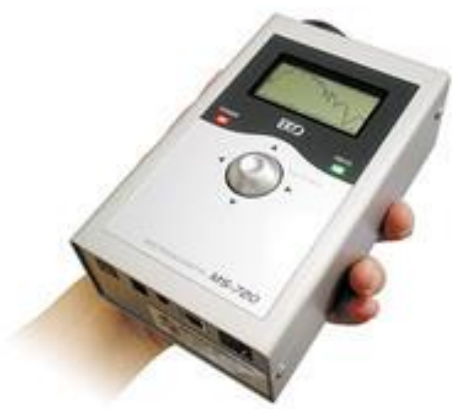

Fig. 10. Measuring instrument for surface reflectance, PAR, and NDVI

TABLE I. MAJOR SPECIFICATION OF MS-720

\begin{tabular}{|c|c|}
\hline Wavelength coverage & $350 \sim 1,050 \mathrm{~nm}$ \\
\hline Wavelength interval & $3.3 \mathrm{~nm}$ \\
\hline Wavelength resolution & $10 \mathrm{~nm}$ \\
\hline Wavelength accuracy & Less than $0.3 \mathrm{~nm}$ \\
\hline Full aperture & $180^{\circ}$ \\
\hline Stray light & Less than $0.15 \%$ \\
\hline Temperature dependency & $\pm 5 \%$ \\
\hline Output Unit & W/m $/ \mu \mathrm{mm}$ or $\mu \mathrm{mol} / \mathrm{m}^{2} / \mathrm{s} / \mu \mathrm{m}$ \\
\hline Measurement time & $0.005 \sim 5 \mathrm{sec}$ \\
\hline
\end{tabular}

Field experiments are conducted at the Saga Prefectural Tea Institute: SPTI situated at 33:07:03.9 N, 129:59:47.0 E on June 1 2008. The first harvesting is finished in the begging of May. After the harvesting of tealeaves, the top tea trees are used to be cut out. Then new tealeaves appear after that. June 1 is middle moment between the first and the second harvests. There are four tea farm areas which are situated North, East, South, and West sides of the SPTI main building as shown in Figure 11.

Figure 12 shows Proposed simple LAI monitoring method with cameras with $\mathrm{p}$ and $\mathrm{s}$ polarization films attached fish eye lens that allows calculation of Degree of Polarization: DP results in estimation of LAI together with examples of $p$ and $s$ polarized radiance images of new tealeaves acquired at Ureshino Saga Japan tea estate on June 12008.

Figure 13 shows typical new tealeaves grow process from the top view of tea estate. Typically, new tealeaves appear in the early April and are harvested in the late April or the early May.
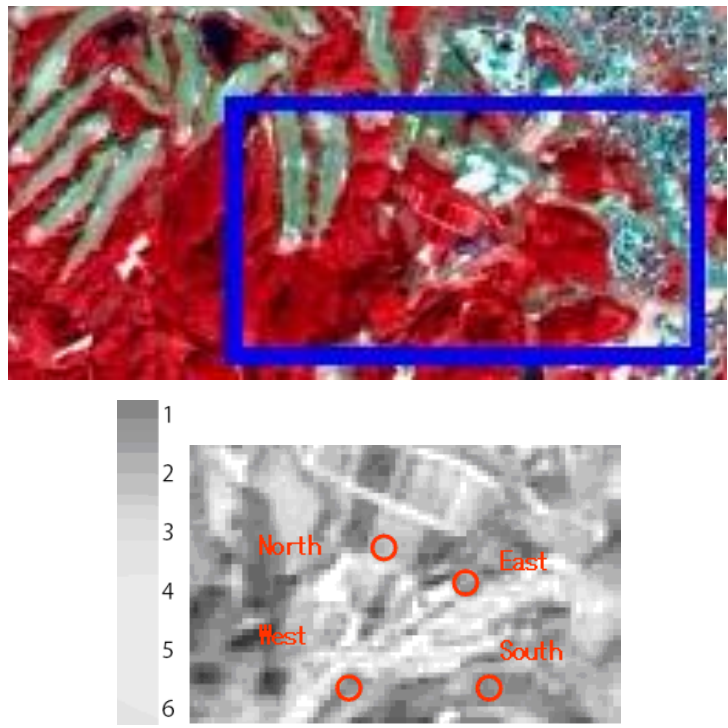

Fig. 11. Enlarged ASTER/VNIR image and total nitrogen contents in tealeaves at the tea estate (Red circles shows tea estates. Grayscale shows $\mathrm{TN} \%$ of nitrogen contents in tealeaves derived from equation (1) of $\mathrm{TN}=22.474 \operatorname{Ref}(\mathrm{Band} \# 3)-10.177)$ : Tea farm areas in concern situated at SPTI (33:07:03.9 N, 129:59:47.0 E)

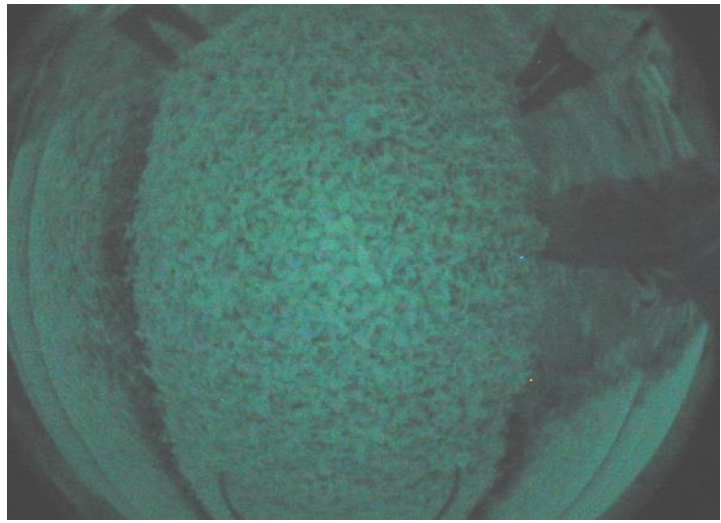

(a) Example of $\mathrm{p}$ polarized radiance of new tealeaves

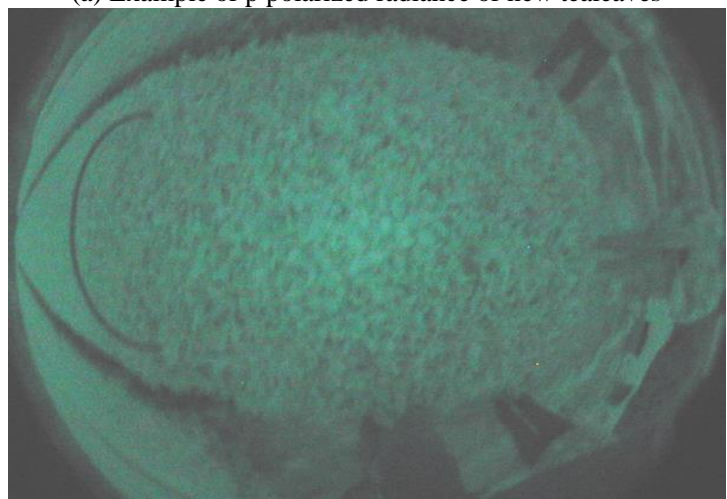

(b) Example of s polarized radiance of new tealeaves

Fig. 12. Proposed simple LAI monitoring method with cameras with $\mathrm{p}$ and $\mathrm{s}$ polarization films attached fish eye lens that allows calculation of Degree of Polarization: DP results in estimation of LAI together with examples of $p$ and $s$ polarized radiance images of new tealeaves acquired at Ureshino Saga Japan tea estate on June 12008. 
Then new tealeaves grow up again in June and are harvested in July. After that new tealeaves grow up again and are harvested in September or October. After all, old tealeaves are cut a little bit for preparation of cold winter season. The idea proposed here is to evaluate vitality of the tea trees through evaluation of total nitrogen and fiber contents by using network cameras monitored in the winter season after harvesting new tealeaves. Such method that allows estimation of vitality of the tea trees is to use measured reflectance at $870 \mathrm{~nm}$ acquired with NIR network cameras.

Reflectance at $550 \mathrm{~nm}$ and $870 \mathrm{~nm}$ together with GM: Green Meter value ${ }^{2}$, Grow index, total nitrogen content, fiber content as well as water content are measured at the Prefectural tea research institute of Saga which is situated in Ureshino-city in April.

Through a comparison between measured total nitrogen and fiber content and estimated reflectance derived from the NIR camera data, Figure 14 of relationship is obtained. From this relation, the following equations are derived through linear regressive analysis,

$\mathrm{TN}=22.474 \operatorname{Ref} 870-10.177$

F-NIR=-22.886Ref870 + 16.699

where TN and F-NIR denote Total Nitrogen and Fiber content in tealeaves.

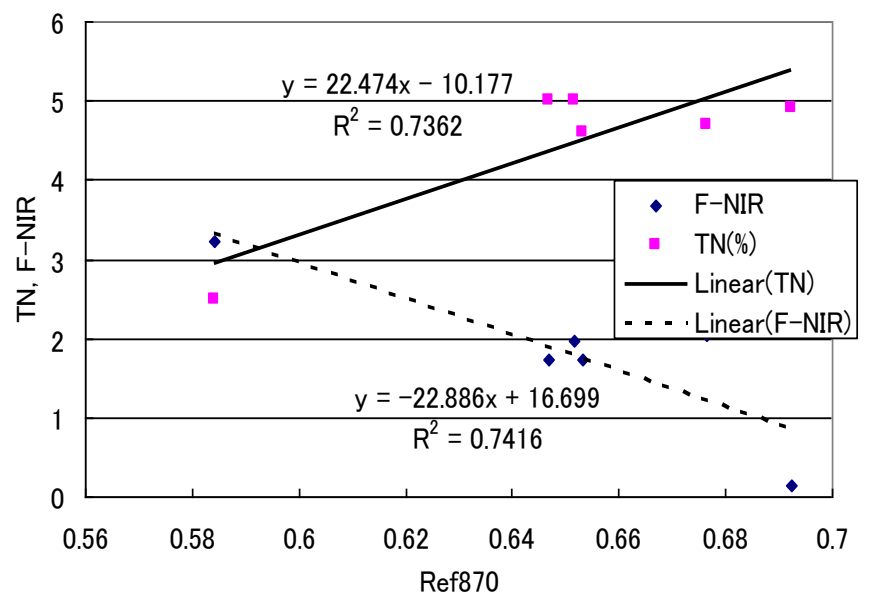

Fig. 13. Relation between total nitrogen and fiber contents in tealeaves and reflectance at $870 \mathrm{~nm}$ measured with NIR camera.

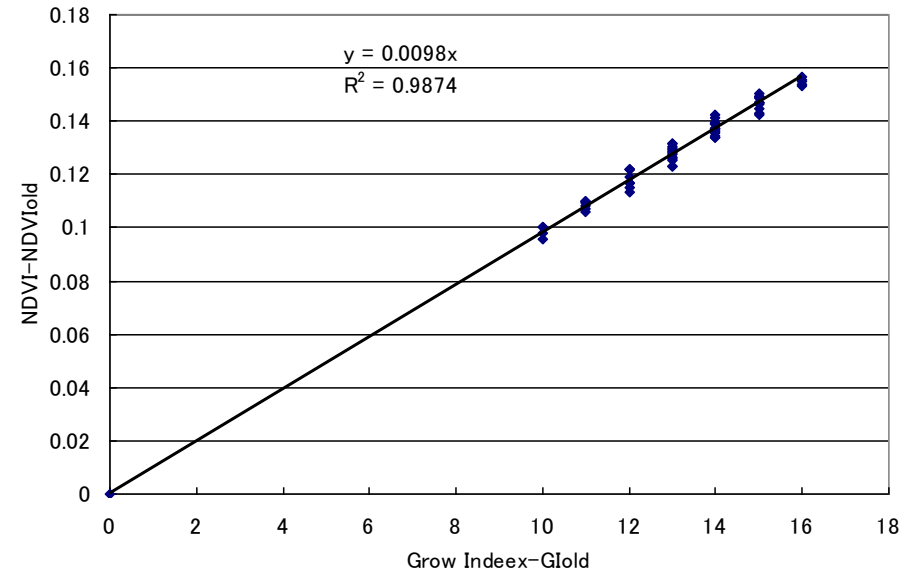

Fig. 14. Relation between Grow index and NDVI

$\mathrm{R}$ square value for $\mathrm{TN}$ is 0.736 while that for F-NIR is 0.742 so that it may say that TN and F-NIR can be estimated with reflectance at $870 \mathrm{~nm}$ derived from NIR network camera.

On the other hand, grow index is also highly correlated to reflectance measured at $870 \mathrm{~nm}$. Grow index is defined as the ratio of the number of new tealeaves to the total number of tealeaves. In accordance with new tealeaves grow up, grow index is getting large. The grow index, essentially, highly correlated to NDVI,

NDVI=(Ref870-Ref550)/(Ref550+Ref870)

and GM. Figure 14 shows the relation between GI and NDVI where GIold $=56$ and $\operatorname{Ref} 870=0.55518$ as well as NDVI $=0.562677$.

In the figure, the horizontal axis shows GI-GIold while the vertical axis shows NDVI-NDVIold. Suffix of old denotes that the tea estate covers with old tealeaves only. In accordance with growing tealeaves, the number of new tealeaves is getting large results in increasing of GI as well as NDVI. Grow Index: GI is expressed with the equation (4) through a linear regressive analysis.

$\mathrm{GI}=102.041 \mathrm{NDVI}$

Thus TN, F-NIR and GI can be estimated with Visible and NIR of network cameras data.

Measured DP, LAI, and NDVI are shown in Table 2.

\footnotetext{
2 http://www.geocities.co.jp/nettaikaju/Observation4-04.html(Access
} on Jan.5 2009) 
TABLE II. MEASURED DP, LAI, AND NDVI

\begin{tabular}{|l|c|c|c|c|c|c|c|c|c|}
\hline DP@675nm & 0.269 & 0.251 & 0.261 & 0.268 & 0.288 & 0.181 & 0.218 & 0.286 & 0.289 \\
\hline LAI & 6.49 & 6.23 & 6.55 & 6.46 & 7.01 & 4.11 & 5.34 & 6.95 & 7.13 \\
\hline & & & & & & & & & \\
NDVI & 0.498 & 0.497 & 0.497 & 0.498 & 0.494 & 0.438 & 0.485 & 0.495 & 0.498 \\
\hline & & & & & & & & & \\
PAR $\left[\mathrm{W} / \mathrm{m}^{2}\right]$ & 0.105 & 0.105 & 0.065 & 0.08 & 0.0138 & 0.02 & 0.0195 & 0.02 & 0.02 \\
\hline
\end{tabular}

Through a regressive analysis, Figure 15 is obtained. Linear regressive equations for representations of LAI, NDVI and PAR are shown in the figure. Although $\mathrm{R}$ square value for PAR is not good enough, other LAI and NDVI can be estimated with measured DP data at $675 \mathrm{~nm}$ observed with 30 degree of observation angle.

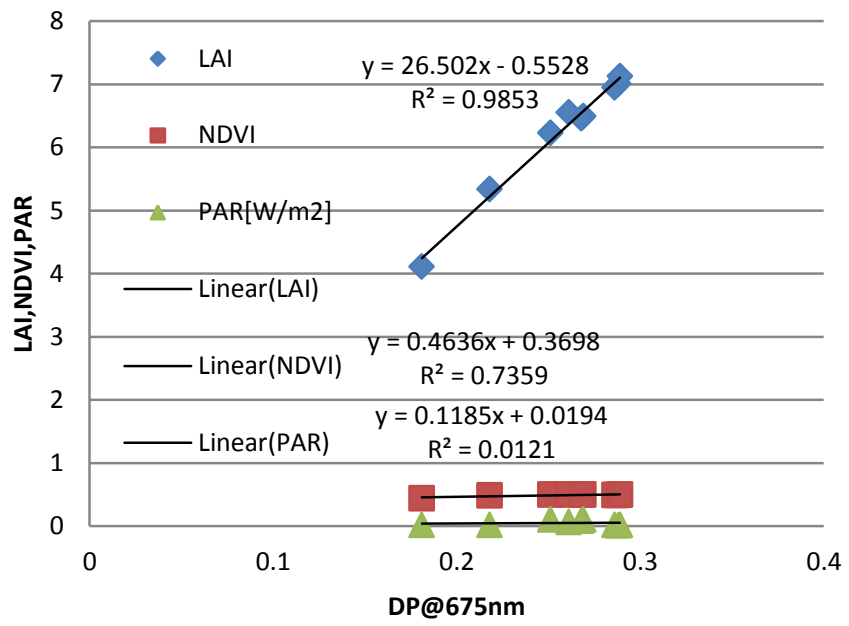

Fig. 15. Results from the regressive analysis between DP at $675 \mathrm{~nm}$ wavelength and LAI, NDVI, PAR.

\section{CONCLUSION}

Method for tealeaves quality estimation through measurements of Degree of Polarization: DP, Leaf Area Index: LAI, Photosynthesis Available Radiance: PAR and Normalized Difference Vegetation Index: NDVI for characterization of tealeaves is proposed. The method allows estimations of PAR, NDVI, Grow Index: GI by using measured Degree of Polarization: DP of tealeaves. Through experiments at the tea farm areas, it is found that the proposed method is validated. Also, the method is validated through Monte Carlo Ray Tracing: MCRT simulations for discrimination between prolate and oblate shapes of tealeaves. In accordance with growing tealeaves, prolate shape of tealeaves changes their shape to oblate shape. Therefore, growing stage can be estimated with DP measurements.

Through simulations and experiments, it is found that the difference between prolate and oblate shapes of tealeaves at $550 \mathrm{~nm}$ (green band) is much clear than that of $730 \mathrm{~nm}$ (near infrared band). It is also found that the difference of DP for different reflectance for $\mathrm{p}$ and s polarized reflectance is much greater than that for same reflectance.

DP difference between prolate and oblate shapes of tealeaves for both same and different reflectance at $\mathrm{p}$ and $\mathrm{s}$ polarization at around 30 degree of observation angle shows relatively clear than that for the other observation angle. Therefore, 30 degree of observation angle would be the best for DP observations.

Total nitrogen content in tealeaves can be expressed with measured DP together with fiber content in Near Infrared wavelength region. Also, grow index, leaf area index can be expressed with measured DP. Although R square value for PAR is not good enough, other LAI and NDVI can be estimated with measured DP data at $675 \mathrm{~nm}$ observed with 30 degree of observation angle.

\section{ACKNOWLEDGMENT}

The author would like to thank Mr. Yasunori Terayama for his efforts through experiments and simulations.

\section{REFERENCES}

[1] J.T.Compton, Red and photographic infrared linear combinations for monitoring vegetation, Journal of Remote Sensing of Environment, 8, 127-150, 1979 .

[2] C.Wiegand, M.Shibayama, and Y.Yamagata, Spectral observation for estimating the growth and yield of rice, Journal of Crop Science, 58, 4, 673-683, 1989.

[3] S.Tsuchida, I.Sato, and S.Okada, BRDF measurement system for spatially unstable land surface-The measurement using spectroradiometer and digital camera- Journal of Remote Sensing, 19, 4, 49-59, 1999.

[4] K.Arai, Lecture Note on Remote Sensing, Morikita-shuppan Co., Ltd., 2000

[5] K.Arai and Y.Nishimura, Degree of polarization model for leaves and discrimination between pea and rice types of leaves for estimation of leaf area index, Abstract, COSPAR 2008, A3.10010-08\#991, 2008.

[6] K.Arai and Long Lili, BRDF model for new tealeaves and new tealeaves monitoring through BRDF monitoring with web cameras, Abstract, COSPAR 2008, A3.10008-08\#992, 2008.

[7] Kohei Arai, Y.lisaka and X.Linag, Aerosol parameter estimation with changing observation angle of hround based polarization radiometer, Advances in Space Research, 39, 1, 28-31, 2007

[8] Ding Ya Liu, Kohei Arai, Forest parameter estimation based on radiative transfer model of Monte Carlo Simulation taking into account crown closer models, Journal of Japan Society of Remote Sensing, 27、2、 141-152、 2007

[9] Yaliu Ding, Kohei Arai, Forest parameter estimation, by means of Monte- Carlo simulations with experimental consideration of estimation of multiple reflections among trees depending on forest parameters, Advances in Space Research, 43, 3, 438-447, 2009.

[10] Kohei Arai and Yui Nishimura, Polarization model for discrimination of broad and needle shaped leaves and estimation of LAI using polarization measurements, Advances in Space Research, 44, 510-516, 2009.

[11] Kohei Arai, Method for estimation of grow index of tealeaves based on Bi- Directional reflectance function: BRDF measurements with ground based network cameras, International Journal of Applied Science, 2, 2, 52-62, 2011.

[12] Kohei Arai, Method for estimation of total nitrogen and fiber contents in tealeaves with ground based network cameras, International Journal of Applied Science, 2, 2, 21-30, 2011.

[13] K.Arai, Monte Carlo ray tracing simulation for bi-directional reflectance distribution function and grow index of tealeaves estimations, International Journal of Research and Review on Computer Science, 2, 6, 1313-1318, 2012.

[14] K.Arai, Fractal model based tea tree and tealeaves model for estimation of well opened tealeaf ratio which is useful to determine tealeaf harvesting timing, International Journal of Research and Review on Computer Science, 3, 3, 1628-1632, 2012.

[15] K.Arai, Y.Terayama, Monte Carlo ray tracing simulation of polarization characteristics of sea water which contains spherical and non-spherical 
shapes of suspended solid and phytoplankton, International Journal of Advanced Computer Science and Applications, 3, 6, 85-89, 2012.

[16] Kohei Arai, Hideo Miyazaki, Masayuki Akaishi, Determination method for tealeaves harvesting with visible to near infrared cameras, Journal of Japanese Society for Remote Sensing and Photogrammetry 51, 1, 38-45, 2012

[17] Greivenkamp, John E., Field Guide to Geometrical Optics. SPIE Field Guides vol. FG01. SPIE. ISBN 0-8194-5294-7, 2004.

[18] Seto R H. Nakamura, F. Nanjo, Y. Hara, Bioscience, Biotechnology, and Biochemistry, Vol.61 issue9 1434-1439 1997.

[19] Sano M, Suzuki M ,Miyase T, Yoshino K, Maeda-Yamamoto, M.J.Agric.Food Chem., 47 (5), 1906-1910 1999.

[20] Kohei Arai, Fundamental Theory for Remote Sensing, Gakujutu-ToshoShuppan Publishing Co. Ltd., 1998.

\section{AUTHORS PROFILE}

Kohei Arai, He received BS, MS and PhD degrees in 1972, 1974 and 1982, respectively. He was with The Institute for Industrial Science and Technology of the University of Tokyo from April 1974 to December 1978 also was with National Space Development Agency of Japan from January, 1979 to March, 1990. During from 1985 to 1987, he was with Canada Centre for Remote Sensing as a Post Doctoral Fellow of National Science and Engineering Research Council of Canada. He moved to Saga University as a Professor in Department of Information Science on April 1990. He was a councilor for the Aeronautics and Space related to the Technology Committee of the Ministry of Science and Technology during from 1998 to 2000. He was a councilor of Saga University for 2002 and 2003. He also was an executive councilor for the Remote Sensing Society of Japan for 2003 to 2005. He is an Adjunct Professor of University of Arizona, USA since 1998. He also is Vice Chairman of the Commission "A" of ICSU/COSPAR since 2008. He wrote 30 books and published 442 journal papers 